\title{
Stability of extracts from pollens of allergenic importance in Korea
}

Kyoung Yong Jeong, Ji Eun Yuk, Jongsun Lee, Seok Woo Jang, Kyung Hee Park, Jae-Hyun Lee, and Jung-Won Park

Department of Internal Medicine, Institute of Allergy, Yonsei University College of Medicine, Seoul, Korea

Received: June 18, 2018

Revised : September 20, 2018

Accepted: September 28, 2018

\section{Correspondence to}

Jung-Won Park, M.D.

Department of Internal Medicine, Institute of Allergy, Yonsei University College of Medicine, 50-1 Yonsei-ro, Seodamun-gu,

Seoul 03722, Korea

Tel: +82-2-2228-1961

Fax: $+82-2-362-8647$

E-mail: parkjw@yuhs.ac
Background/Aims: Accurate diagnosis and the effects of allergen-specific immunotherapy for pollinosis are greatly dependent on the potency and stability of the extract. This study aimed to examine factors, such as temperature and storage buffer composition, that affect the stability of allergen extracts from pollens of allergenic importance in Korea.

Methods: We prepared four pollen allergen extracts from ragweed, mugwort, Japanese hop, and sawtooth oak, which are the most important causes of seasonal rhinitis in Korea. Changes of protein and major allergen concentration were measured over 1 year by Bradford assay, two-site enzyme-linked immunosorbent assay, and sodium dodecyl sulfate-polyacrylamide gel electrophoresis after reconstitution of the lyophilized allergen extract in various buffers and stored at room temperature (RT, $18^{\circ} \mathrm{C}$ to $26^{\circ} \mathrm{C}$ ) or refrigerated $\left(4^{\circ} \mathrm{C}\right)$.

Results: More than $90 \%$ of the original protein concentration in all four extracts examined was detected over 1 year when $50 \%$ glycerol was added and refrigerated, whereas $57.9 \%$ to $94.5 \%$ remained in the extracts at RT. The addition of $50 \%$ glycerol to the storage buffer was found to prevent protein degradation at RT. Amb a 1, a major allergen of ragweed, was almost completely degraded in 9 weeks at RT when reconstituted in a buffer without $50 \%$ glycerol. However, $55.6 \%$ to $92.8 \%$ of $\mathrm{Amb}$ a 1 content was detected after 1 year of incubation at $4^{\circ} \mathrm{C}$ in all buffer conditions except $0.3 \%$ phenol.

Conclusions: Addition of 50\% glycerol as well as refrigeration was found to be important in increasing the shelf-life of allergen extracts from pollens of allergenic importance.

Keywords: Allergen; Rhinitis, allergic, seasonal; Protein stability

\section{INTRODUCTION}

The diagnosis and effect of allergen-specific immunotherapy are dependent on the quality of allergen extracts. U.S. Food and Drug Administration regulations for allergen extracts state that glycerin extracts can be stored for 3 years, while non-glycerinated extracts should be expired after 1.5 years [1]. However, there is insufficient information on the stability of commercial allergen ex- tracts. Fifty percent glycerol also retards the growth of microbes. However, more than $12 \%$ glycerol in the extract causes pain to patients receiving immunotherapy [2]. Phenol is also commonly used as an anti-microbial reagent. Low concentrations of phenol $(<0.4 \%)$ have no substantial effect on the stability of glycerinated allergen extracts.

In general, storage temperature is the most important factor for the stability of allergen extracts. Timothy grass 
pollen extract in 50\% glycerol is reported to be highly stable during 1-week delivery at room temperature (RT) [3]. Most of the glycerinated allergen extracts are described to be stable at RT for up to 4 weeks [1]. Our study on the stability of house dust mite extract was in line with these observations [4].

In Korea, diagnostic and immunotherapeutic reagents of allergic diseases are being imported from manufacturers in Western countries. Therefore, we produced eight common inhalant allergen skin test reagents, including sawtooth oak and Japanese hop, and evaluated their diagnostic usefulness in comparison with commercial products [5]. In this study, we investigated the stability of newly developed pollen allergen extracts for the labeling of shelf-life.

\section{METHODS}

\section{Serum samples}

Sera were collected from allergic patients who showed $>3.5 \mathrm{kU}_{\mathrm{A}} / \mathrm{L}$ to each pollen by ImmunoCAP (ThermoFisher Scientific, Uppsala, Sweden) at the Allergy-Asthma Center at Severance Hospital, Seoul, Korea. Sera from ten patients were pooled for each allergen (age range 22 to 61 year, average 44 for ragweed; age range 24 to 63 year, average 42 for mugwort; age range 24 to 59 year, average 37 for Japanese hop; age range 7 to 38 year, average 14 for oak). Consent from patients was obtained before the collection of blood. This study was approved by the Institutional Review Board of Yonsei University College of Medicine (4-2015-0240).

\section{Preparation of allergen extracts from pollens}

Pollen extracts, which were prepared as described previously $[4,5]$, were obtained from Prolagen (Seoul, Korea). In short, allergens were extracted in phosphate buffered saline ( $\mathrm{pH}$ 7.4) after defatting with ethyl ether, dialyzed against distilled water, filtered ( $0.22 \mu \mathrm{m}$, Millipore, Bedford, MA, USA), freed-dried, and kept at $-70^{\circ} \mathrm{C}$ until use.

\section{Storage of pollen extracts}

The extracts were dissolved in one of four solutions: normal saline, $50 \%$ glycerol, $0.3 \%$ phenol saline and 10\% glycerol, and $0.3 \%$ phenol and 50\% glycerol. The reconstituted extracts were aliquoted and stored at $4^{\circ} \mathrm{C}$ and
$\mathrm{RT}\left(15^{\circ} \mathrm{C}\right.$ to $\left.25^{\circ} \mathrm{C}\right)$. The samples were withdrawn at weeks $1,2,4,9,13,26$, and 52 and kept at $-70^{\circ} \mathrm{C}$.

\section{Measu rements of protein and Amb a 1 content}

Protein concentrations were determined by Bradford assay (Bio-Rad, Hercules, CA, USA) with bovine serum albumin as a standard. Amb a 1 content in the ragweed extract was measured using a two-site enzyme-linked immunosorbent assay (ELISA) kit (Indoor Biotechnologies Inc., Charlottesville, VA, USA).

\section{Assessment of allergen potency}

The potency of the extracts was determined by inhibition ELISA. Each well was coated with $100 \mu \mathrm{L}$ of $10 \mu \mathrm{g} /$ $\mathrm{mL}$ of each allergen extract in $50 \mathrm{mM}$ sodium bicarbonate buffer ( $\mathrm{pH}$ 9.6). Serum samples (1:4 dilutions; pooled sera from 10 patients, specific immunoglobulin $\mathrm{E}$ [IgE] to each allergen $>0.35 \mathrm{kU}_{\mathrm{A}} / \mathrm{L}$ ), which were preincubated with various concentration of inhibitors $(22 \mu \mathrm{L}$ samples with $88 \mu \mathrm{L}$ of sera) were added and incubated for 1 hour. IgE antibodies were detected with biotinylated goat anti-human IgE (Vector, Burlingame, CA, USA) and streptavidin-peroxidase (Sigma-Aldrich, Sydney, Australia). The percentage of inhibition was calculated as $\left(1-\mathrm{A}_{\mathrm{i}} /\right.$ $\left.A_{o}\right) \times 100$, where $A_{i}$ stands for the absorbance at $450 \mathrm{~nm}$ with inhibitor, and $A_{0}$ for the absorbance without inhibitor.

\section{Sodium dodecyl sulfate-polyacrylamide gel electro- phoresis and IgE immunoblotting}

Pollen extracts ( $20 \mu \mathrm{L}$ each) were separated on $15 \%$, for ragweed, mugwort, and sawtooth oak, and $18 \%$, for Japanese hop, sodium dodecyl sulfate-polyacrylamide gel electrophoresis under reducing conditions. After the separation of proteins, gels were stained with Coomassie blue or transferred onto polyvinylidene difluoride membranes (GE Waters \& Process Technologies, Trevose, PA, USA). IgE reactive components were detected with pooled patients' sera $(1: 4, \mathrm{n}=10)$ and alkaline phosphate conjugated goat anti-human $\operatorname{IgE}(1: 1,000)$ ( $\varepsilon$-chain specific, Sigma-Aldrich). The color was developed with nitroblue tetrazolium and 3-bromo-4-chloro-5-indolylphosphate (Promega, Madison, WI, USA). 

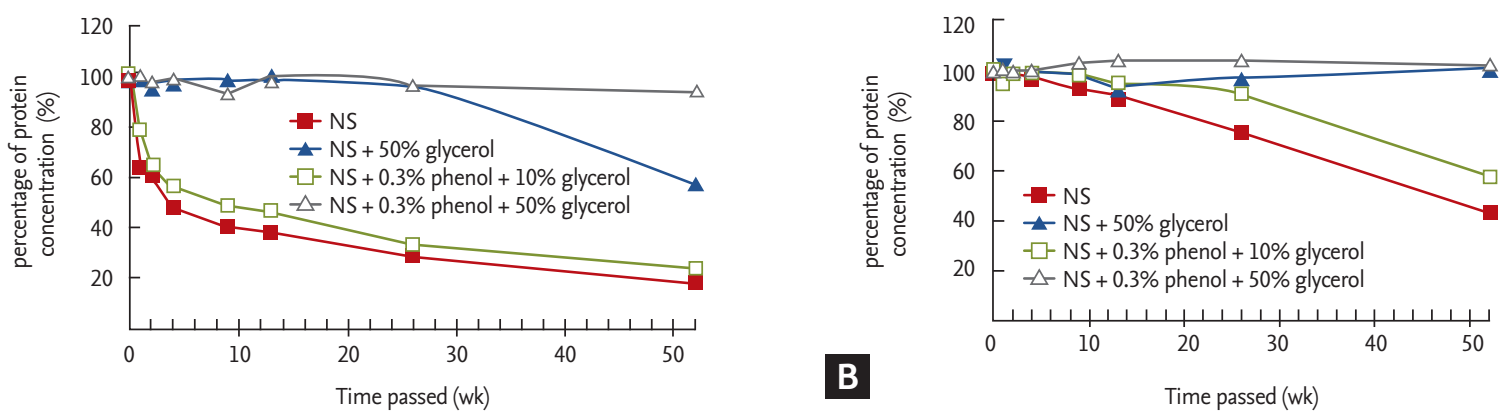

C
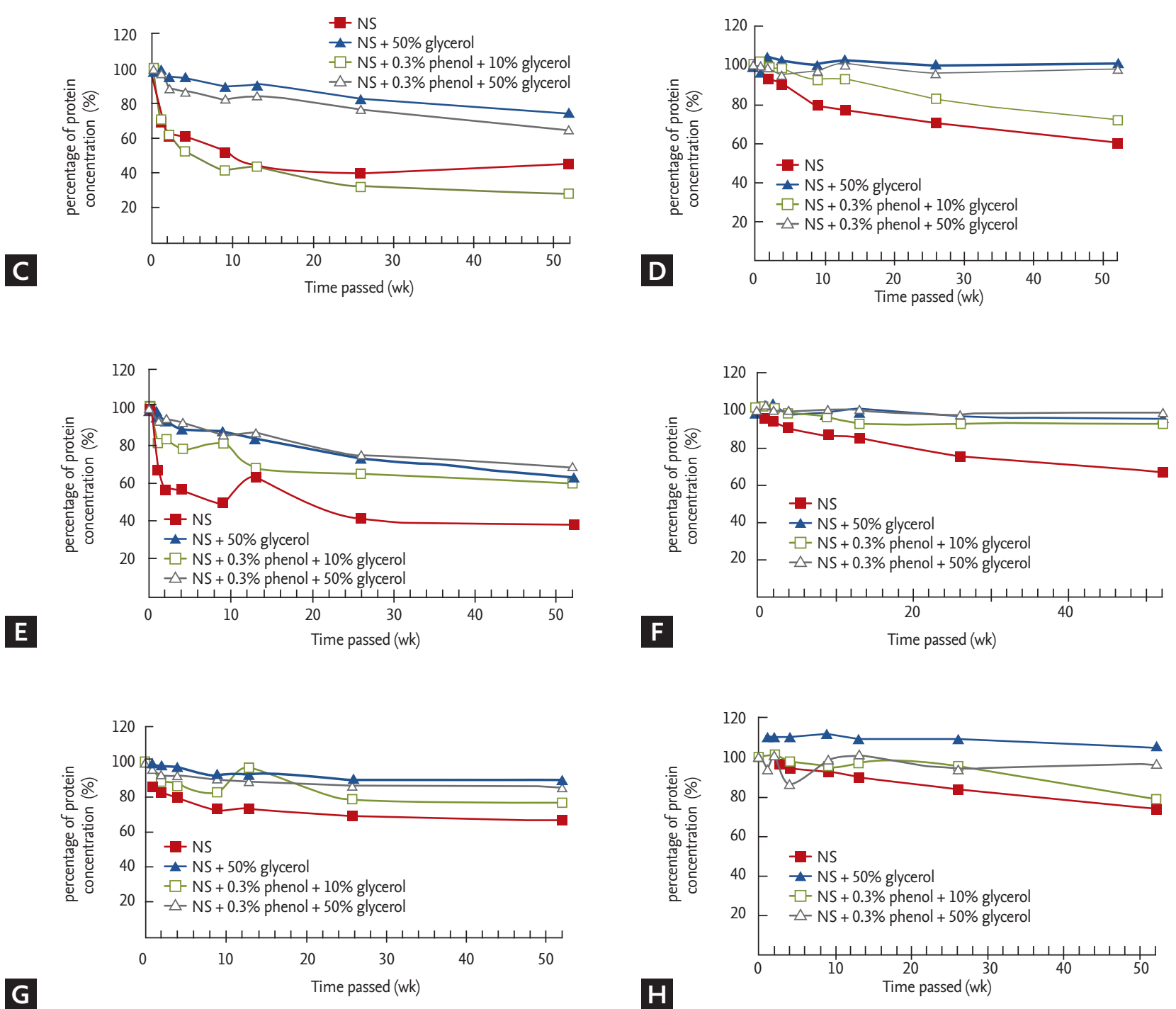

Figure 1. Change of protein concentration in pollen extracts over 1 year of storage at various conditions. Protein concentration, measured by Bradford assay, in ragweed extract stored at room temperature $(\mathrm{A})$ and at $4^{\circ} \mathrm{C}(\mathrm{B})$, mugwort at room temperature $(\mathrm{C})$ and at $4^{\circ} \mathrm{C}(\mathrm{D})$, Japanese hop at room temperature $(\mathrm{E})$ and at $4^{\circ} \mathrm{C}(\mathrm{F})$, sawtooth oak at room temperature $(\mathrm{G})$ and at $4^{\circ} \mathrm{C}(\mathrm{H}) . \mathrm{NS}$, normal saline. 


\section{RESULTS}

\section{Effect of storage conditions on the protein concen- tration of pollen extracts}

The stability of all the pollen extracts was best when 50\% glycerol was added to the storage buffer. At least $57.9 \%$ of the initial protein in all the pollen extracts was preserved over 1 year at RT when the extracts were dissolved in 50\% glycerol solution (Fig. 1). However, $54.9 \%$ to $91.4 \%$ of the protein content of ragweed and mugwort pollen extracts were degraded by the same storage conditions. Interestingly, $59.9 \%$ of the Japanese hop protein content remained over 1 year in the presence of $10 \%$ glycerol at RT, while 37.8\% remained in normal saline. Oak pollen extract was shown to be relatively stable. However, it also showed improved stability in the presence of $50 \%$ glycerol (85.7\% to $89.3 \%)$, compared to normal saline or $10 \%$ glycerol in phenol saline (66.6\% to $76.9 \%)$.

When refrigerated, at least $95 \%$ of the protein content of all the extracts was stable over 1 year when $50 \%$ glycerol was included. Less than $77.8 \%$ of protein remained after 1 year of storage in the refrigerator without 50\% glycerol. The addition of $10 \%$ glycerol seemed to be protective in the case of the Japanese hop pollen extract (92.1\% in $10 \%$ glycerol in phenol saline).

\section{Effect of storage conditions on protein profile and IgE reactive components}

Notable changes of protein bands were observed in a 38 $\mathrm{kDa}$ protein (Amb a 1) for ragweed, a $24 \mathrm{kDa}$ protein for mugwort, a $12 \mathrm{kDa}$ protein (a putative major allergen) from Japanese hop, and a $17 \mathrm{kDa}$ protein for sawtooth oak pollen extracts (Fig. 2). IgE immunoblotting was performed for the extracts, which were dissolved in normal saline and phenol saline with 50\% glycerol at RT (Fig. 3). In IgE immunoblot analyses, a significant change of IgE reactivity to the above-mentioned components was shown. Additionally, a $25 \mathrm{kDa}$ protein from Japanese hop which seems to be highly unstable was detected.

\section{Effect of storage condition on Amb a 1 content in ragweed pollen extract}

A high level of Amb a 1 was sustained for 52 weeks when refrigerated (Fig. 4). At the 52nd week, $2.4 \%$ of Amb a 1 remained in normal saline, $73.6 \%$ in 50\% glycerol, o\% in phenol saline in $10 \%$ glycerol, and $46.6 \%$ in phenol saline in 50\% glycerol at RT. When refrigerated for 52 weeks, $55.6 \%$ of Amb a 1 remained in normal saline, $85.1 \%$ in $50 \%$ glycerol, $67.8 \%$ in phenol saline in $10 \%$ glycerol, and $92.8 \%$ in phenol saline in $50 \%$ glycerol.

\section{Effect of the storage condition on the allergen potency}

Change of overall IgE reactivity of the extracts was measured by the inhibition of ELISA. No significant loss of $\operatorname{IgE}$ reactivity was found for the extracts that were refrigerated (Fig. 5). Interestingly, ragweed and sawtooth oak pollen extracts stored at RT were very stable (86.7 to $97.8 \%$ IgE reactivity retained). In the case of mugwort and Japanese hop, potency was maintained for over 1 year only in the presence of phenol saline in $50 \%$ glycerol (94.3\% and 82.7\%, respectively).

\section{DISCUSSION}

In this study, we assessed the stability of allergen extracts from pollens of allergenic importance in Korea: ragweed, mugwort, Japanese hop, and sawtooth oak $[6,7]$. Changes in the protein content and potency of pollen extracts that were stored in various conditions were examined over 1 year. In particular, this is the first report on the stability of Japanese hop and sawtooth oak pollen extracts. Interestingly, these two pollen extracts were shown to be more stable compared to ragweed and mugwort pollen extracts in terms of protein content and IgE reactivity (Figs. 1 and 5). However, it is not certain what made this differences, whether protease activity in the extract or stability of protein itself.

IgE reactivity of the extracts was dependent on the intactness of a $26 \mathrm{kDa}$ component (Amb a $1 \alpha$ subchain), a $24 \mathrm{kDa}$ component (Art v 1) for mugwort, a $12 \mathrm{kDa}$ component for Japanese hop, and a $17 \mathrm{kDa}$ component for sawtooth oak (Figs. 2, 3, and 5). Loss of IgE reactivity over time was much slower than those of protein degradation in all pollen extracts. This is probably because of the retention of IgE epitopes even after the partial degradation of allergens. A more abrupt break-down, compared to protein content, support this inference (Fig. 4). Amb a 1 level measured by ELISA in the ragweed pollen extract showed a similar pattern of stability with protein content. Intact Amb a $1(38 \mathrm{kDa})$ is known to be divided 
A

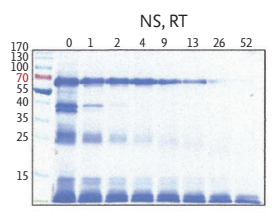

NS, $4^{\circ} \mathrm{C}$

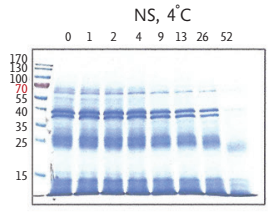

NS, RT

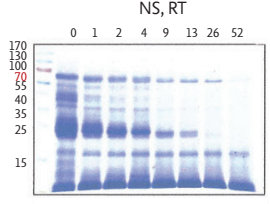

NS, $4^{\circ} \mathrm{C}$

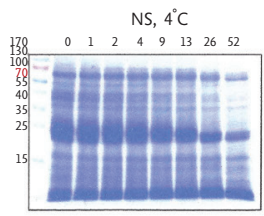

NS, RT

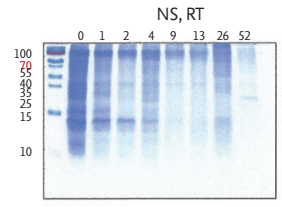

NS, $4^{\circ} \mathrm{C}$

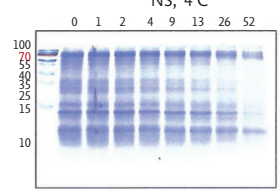

NS, RT

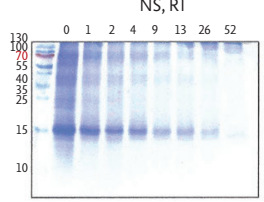

NS, $4^{\circ} \mathrm{C}$

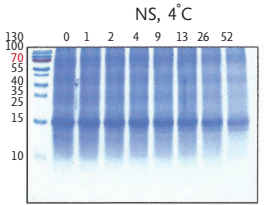

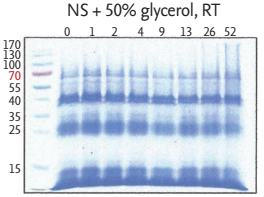

$\mathrm{NS}+50 \%$ glycerol, $4^{\circ} \mathrm{C}$
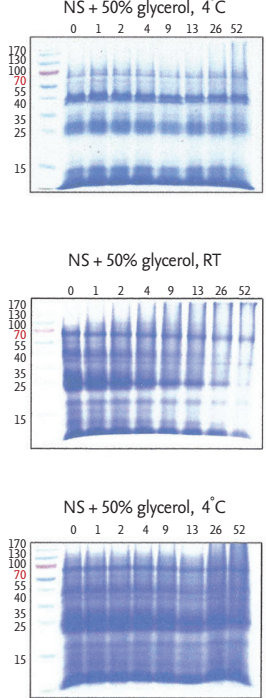

$\mathrm{NS}+50 \%$ glycerol, RT

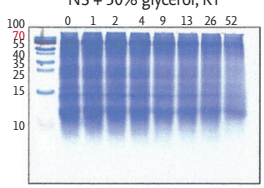

$\mathrm{NS}+50 \%$ glycerol, $4^{\circ} \mathrm{C}$

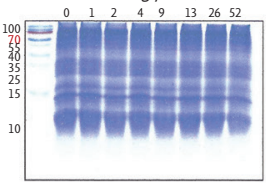

$\mathrm{NS}+50 \%$ glycerol, RT

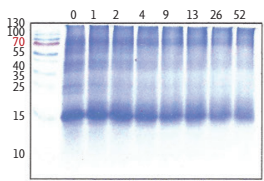

$\mathrm{NS}+50 \%$ glycerol, $4^{\circ} \mathrm{C}$

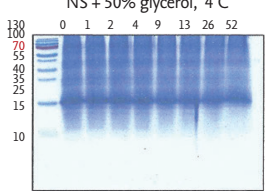

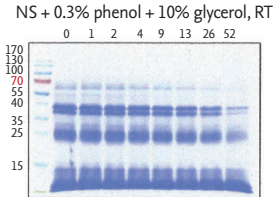

NS $+0.3 \%$ phenol $+10 \%$ glycerol, $4^{\circ} \mathrm{C}$
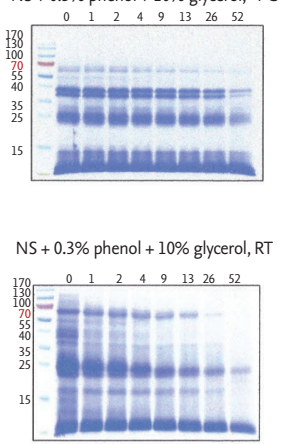

NS $+0.3 \%$ phenol $+10 \%$ glycerol, $4^{\circ} \mathrm{C}$
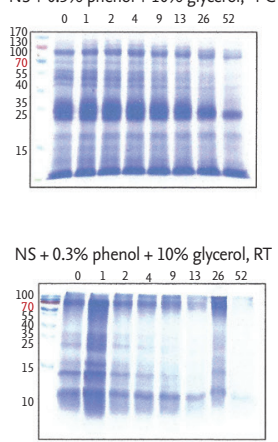

$\mathrm{NS}+0.3 \%$ phenol $+10 \%$

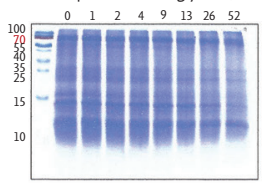

NS $+0.3 \%$ phenol $+10 \%$ glycerol, RT
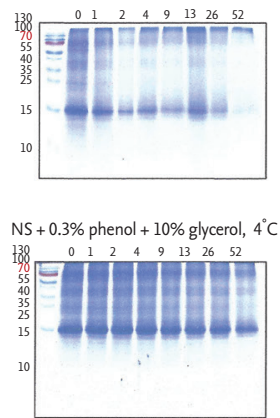
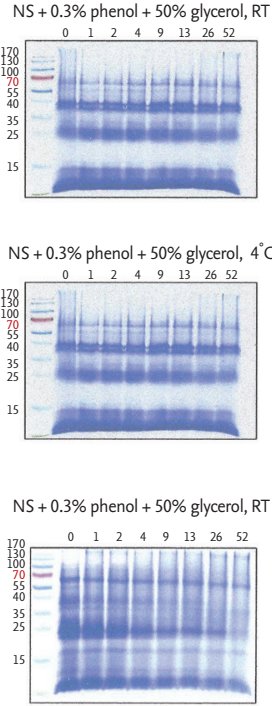

NS $+0.3 \%$ phenol $+50 \%$ glycerol, $4{ }^{\circ} \mathrm{C}$
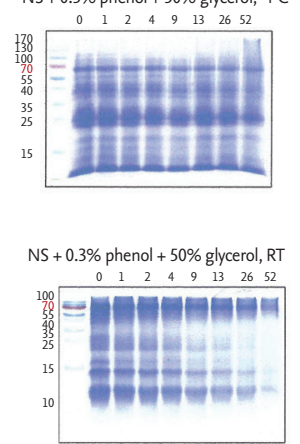

NS $+0.3 \%$ phenol $+50 \%$ glycerol, $4^{\circ} \mathrm{C}$

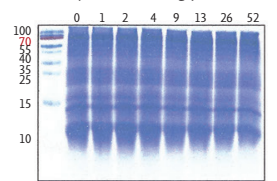

NS + $0.3 \%$ phenol $+50 \%$ glycerol, RT
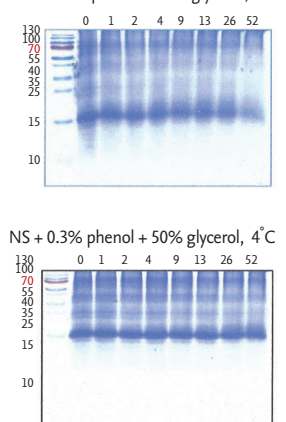

Figure 2. Change of protein profile in the pollen extracts over 1 year of storage in various conditions. Sodium dodecyl sulfate-polyacrylamide gel electrophoresis (SDS-PAGE) of ragweed extract reconstituted in normal saline (NS), in 50\% glycerol, in phenol saline in 10\% glycerol, and in phenol saline in 50\% glycerol kept at room temperature (RT) (A); ragweed in NS, ragweed in 50\% glycerol, ragweed in phenol saline in $10 \%$ glycerol, ragweed phenol saline in $50 \%$ glycerol at $4^{\circ} \mathrm{C}(\mathrm{B})$; mugwort in NS, in $50 \%$ glycerol, in phenol saline in 10\% glycerol, and in phenol saline in 50\% glycerol at RT (C); mugwort in NS, in 50\% glycerol, in phenol saline in 10\% glycerol, and in phenol saline in $50 \%$ glycerol at $4^{\circ} \mathrm{C}(\mathrm{D})$; Japanese hop in NS, in $50 \%$ glycerol, in phenol saline in $10 \%$ glycerol, in phenol saline in 50\% glycerol at RT (E); Japanese hop in NS, in 50\% glycerol, in phenol saline in 10\% glycerol, and in phenol saline in $50 \%$ glycerol at $4^{\circ} \mathrm{C}(\mathrm{F})$; sawtooth oak in NS, in 50\% glycerol, in phenol saline in $10 \%$ glycerol, in phenol saline in $50 \%$ glycerol at RT (G); sawtooth oak in NS, in 50\% glycerol, in phenol saline in $10 \%$ glycerol, and in phenol saline in $50 \%$ glycerol at $4^{\circ} \mathrm{C}(\mathrm{H})$. 
A

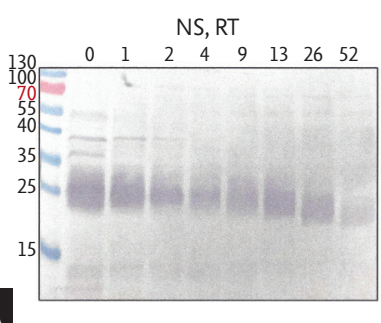

NS, RT

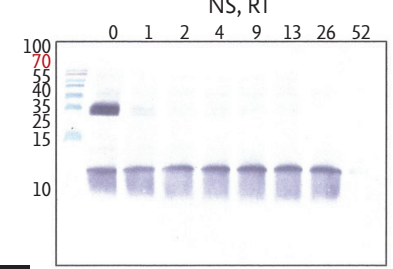

$\mathrm{E}$

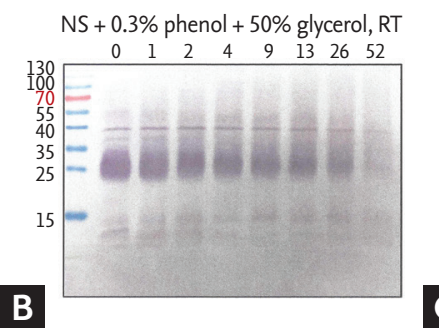

NS $+0.3 \%$ phenol $+50 \%$ glycerol, RT

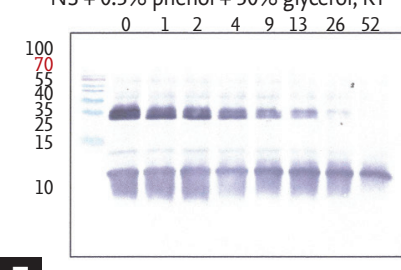

$\mathbf{F}$
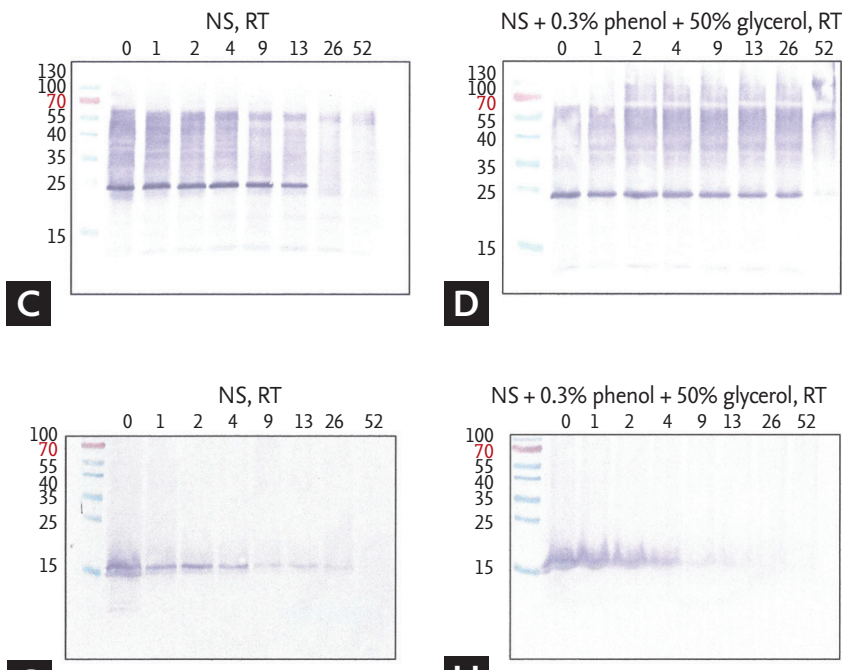

G

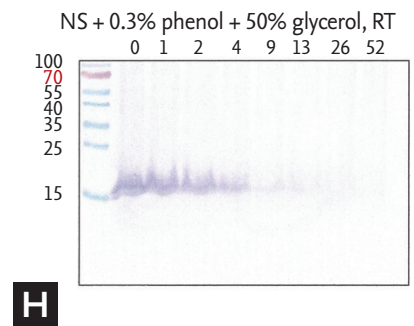

$\mathbf{H}$

Figure 3. Change of immunoglobulin $\mathrm{E}(\mathrm{IgE})$ reactive components in the pollen extracts over 1 year at room temperature (RT). IgE immunoblot analysis of ragweed dissolved in normal saline (NS) (A), ragweed in phenol saline in $50 \%$ glycerol (B), mugwort in NS (C), mugwort in phenol saline in 50\% glycerol (D), Japanese hop in normal saline (E), Japanese hop in phenol saline in $50 \%$ glycerol (F), sawtooth oak in NS (G), and sawtooth oak in phenol saline in $50 \%$ glycerol $(\mathrm{H})$.
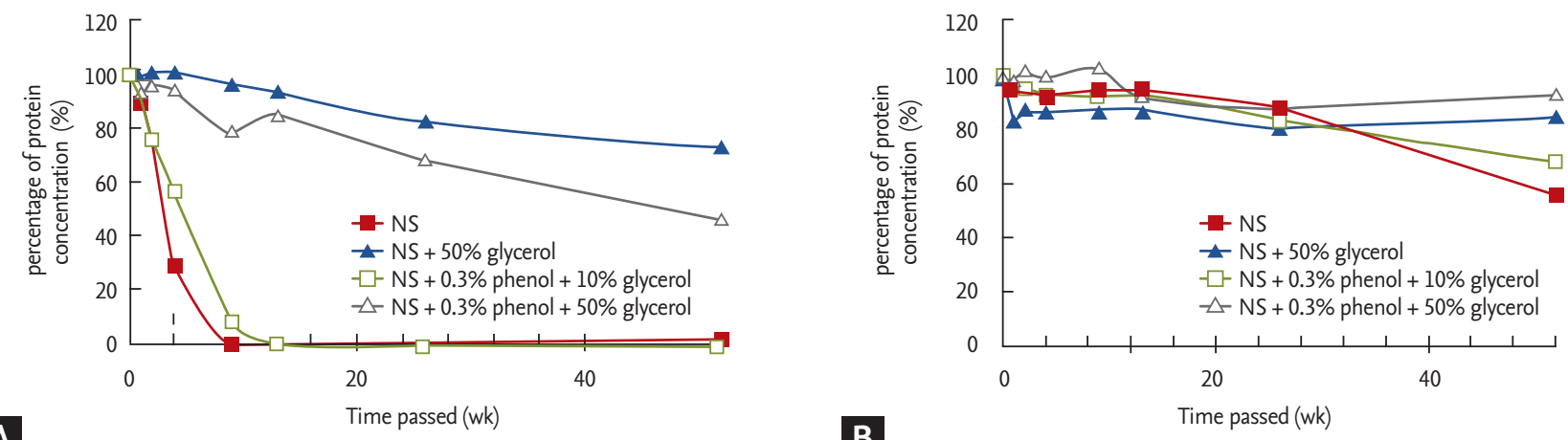

Figure 4. Change of Amb a 1 content in ragweed extract over 1 year in various storage conditions. Amb a 1 content, measured by a two-site enzyme-linked immunosorbent assay, in the extract stored at room temperature (A) was compared with the extract at $4^{\circ} \mathrm{C}(\mathrm{B})$. NS, normal saline.

into 26 ( $\alpha$ subchain) and $12 \mathrm{kDa}(\beta$ subchain) fragments. Recombinant Amb a $1 \alpha$ displayed reduced IgE reactivity and is suggested as a candidate for the development of an immunotherapeutic reagent [8]. However, the $\alpha$ subchain showed a stronger IgE reactivity than the $\beta$ subchain in Korean ragweed allergic subjects (Fig. 3). The change of IgE reactivity was also shown to be consistent with the degradation of $\alpha$ subchain (Figs. 4 and 5).

Another interesting finding is the abrupt destruction of a $34 \mathrm{kDa}$ component from Japanese hop (Fig.
3). In previous studies, most of the IgE antibodies are described to be directed against the $12 \mathrm{kDa}$ component $[9,10]$. Further studies are necessary to characterize this labile $34-\mathrm{kDa}$ component. More detailed characterization of major allergens from sawtooth oak and Japanese hop pollens is needed for the better understanding of IgE reactivity and protein degradation.

As expected all the allergen extracts exhibited improved stability when refrigerated, compared to those stored at RT. The inclusion of 50\% glycerol increased 
A
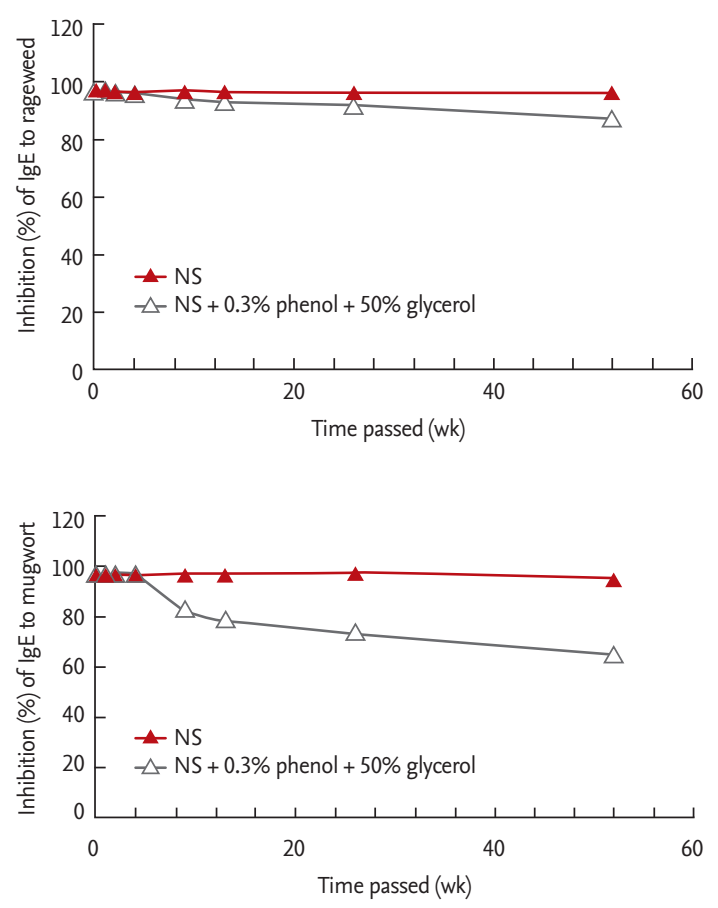

C

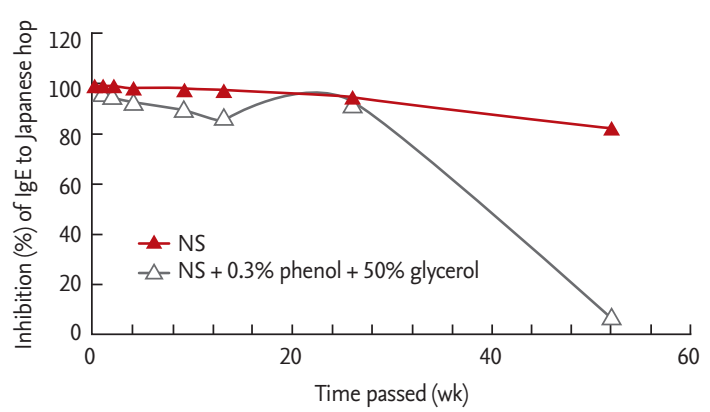

E

G

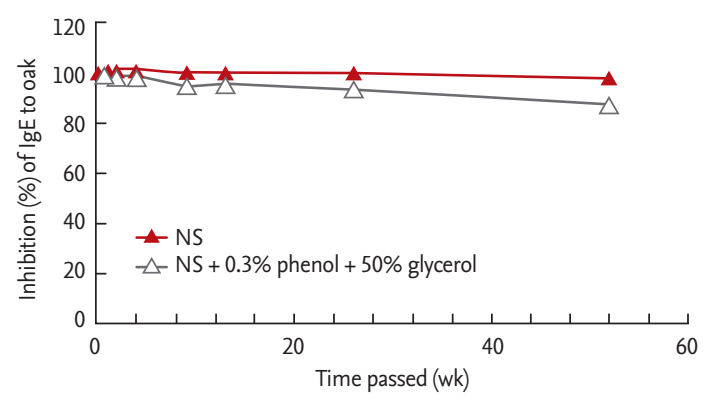

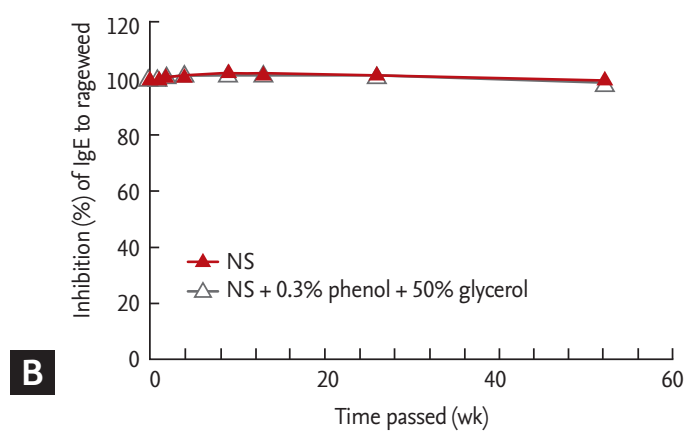

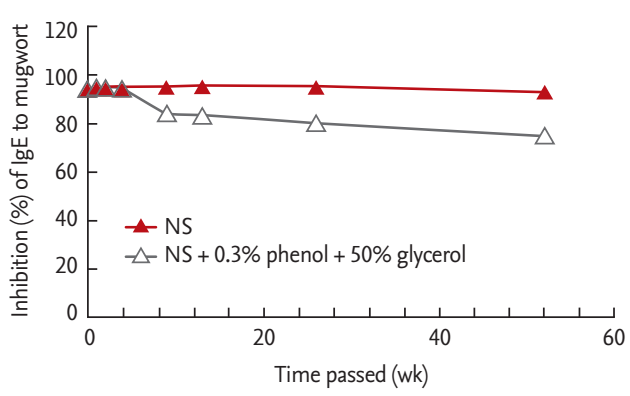

D

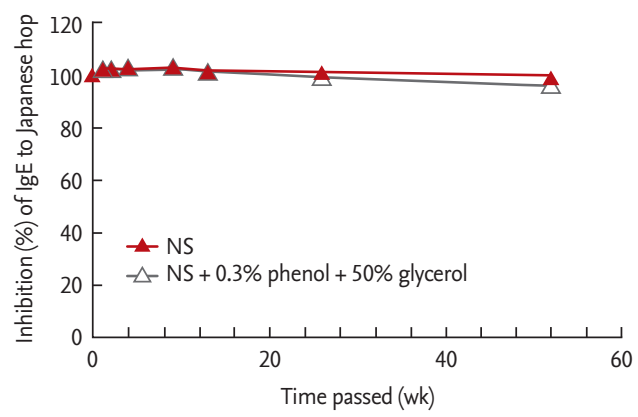

$\mathbf{F}$

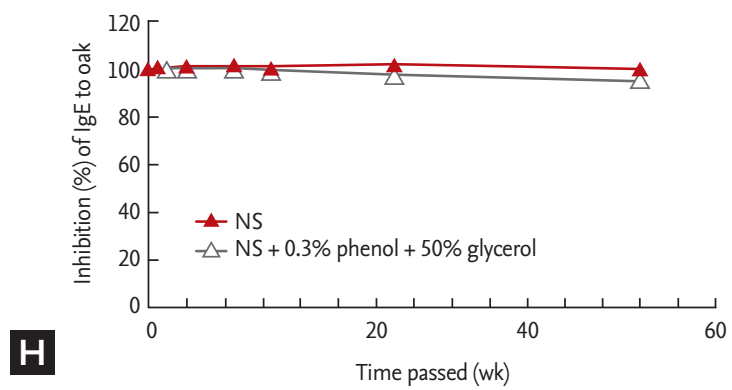

Figure 5. Change of potency and overall immunoglobulin E (IgE) reactivity of the extracts over 1 year of storage. IgE reactivity of the extracts reconstituted in normal saline and phenol saline in $50 \%$ glycerol and kept at room temperature or $4^{\circ} \mathrm{C}$ was compared with the initial states by inhibition enzyme-linked immunosorbent assay. Ragweed at room temperature (A), ragweed at $4^{\circ} \mathrm{C}(\mathrm{B})$, mugwort at room temperature $(\mathrm{C})$, mugwort at $4^{\circ} \mathrm{C}(\mathrm{D})$, Japanese hop at room temperature $(\mathrm{E})$, Japanese hop at $4^{\circ} \mathrm{C}(\mathrm{F})$, sawtooth oak at room temperature $(\mathrm{G})$, and sawtooth oak at $4^{\circ} \mathrm{C}(\mathrm{H})$. NS, normal saline. 
the stability of all the allergen extracts tested. Phenol seems to have a negligible effect on the stability of the extracts. The influence of human serum albumin on the stability of the extracts was not tested for it is known to be effective in a diluted extract [11].

A limitation of this study is the lack of temperature excursions. It may be necessary to examine the consequences of potency at the elevated temperatures during shipping or clinical use. Most of the glycerinated standardized extracts sustain little loss of potency at least for 1 week at RT [1]. Four glycerinated pollen extracts examined in this study also showed no substantial loss of IgE reactivity at RT for a 1-week period (Fig. 5).

Clinical implication of this study is importance of selection of glycerinated extract and renewal of the extract after expiration for stability may influence the accurate diagnosis and effective immunotherapy. Cautious handling of the extracts is also needed. Furthermore, the information obtained in this study will be useful for the development of standardized pollen extracts for diagnosis and treatment.

Taken together, we exhibited optimal conditions for the storage of newly developed pollen extracts. Refrigeration of the extracts is the most important factor in increasing the shelf-life, and the addition of 50\% glycerol can improve the stability of the extracts. The information on the stability of pollen extracts will be useful for the further standardization and development of diagnostic and immunotherapeutic reagents.

\section{KEY MESSAGE}

1. Refrigeration of the extracts is the most important factor in increasing the shelf-life, and the addition of $50 \%$ glycerol can improve the stability of the extracts. This aspect should be kept in mind for clinical use of pollen extracts for the diagnosis and immunotherapy of pollinosis patients.

2. Cautious handling of the extracts also can influence on accurate diagnosis and effective treatment. Study results indicate the importance of selection of glycerinated extract and renewal of the extract after expiration for stability.

\section{Conflict of interest}

Dr. Jung-Won Park reports serving as an unpaid chief technology officer for Prolagen. Dr. Jung-Won Park, Dr. Jae-Hyun Lee, Dr. Kyung Hee Park, and Dr. Kyoung Yong Jeong have an equity interest in Prolagen. The interests of these authors did not influence academic fairness in conducting this study, analyzing results, and writing a paper. Other authors have no potential conflicts of interest to disclose.

\section{Acknowledgments}

This research was supported by a grant of the Korea Health Technology R\&D Project through the Korea Health Industry Development Institute (KHIDI), funded by the Ministry of Health and Welfare, Republic of Korea (grant number: $\mathrm{HI}_{14} \mathrm{Cl}_{324}$ ).

\section{REFERENCES}

1. Plunkett G. Update: stability of allergen extracts to establish expiration dating. Curr Opin Otolaryngol Head Neck Surg 2016;24:261-269.

2. Van Metre TE Jr, Rosenberg GL, Vaswani SK, Ziegler SR, Adkinson NF. Pain and dermal reaction caused by injected glycerin in immunotherapy solutions. J Allergy Clin Immunol 1996;97:1033-1039.

3. Moore M, Tucker M, Grier T, Quinn J. Effects of summer mailing on in vivo and in vitro relative potencies of standardized timothy grass extract. Ann Allergy Asthma Immunol 2010;104:147-151.

4. Jeong KY, Choi SY, Han IS, et al. The effects of storage conditions on the stability of house dust mite extracts. Allergy Asthma Immunol Res 2013;5:397-401.

5. Lee SC, Sim DW, Lee J, et al. Comparison between newly developed and commercial inhalant skin prick test reagents using in vivo and in vitro methods. J Korean Med Sci 2018;33:e101.

6. Jeong KY, Lee JH, Kim EJ, et al. Current status of standardization of inhalant allergen extracts in Korea. Allergy Asthma Immunol Res 2014;6:196-200.

7. Jeong KY, Son M, Park JH, et al. Cross-reactivity between oak and birch pollens in Korean tree pollinosis. J Korean Med Sci 2016;31:1202-1207.

8. Wopfner N, Jahn-Schmid B, Schmidt G, et al. The alpha and beta subchain of Amb a 1, the major ragweed-pollen 
allergen show divergent reactivity at the IgE and T-cell level. Mol Immunol 2009;46:2090-2097.

9. Park JW, Ko SH, Kim CW, Jeoung BJ, Hong CS. Identification and characterization of the major allergen of the $\mathrm{Hu}$ mulus japonicus pollen. Clin Exp Allergy 1999;29:10801086.

10. Jeong KY, Son M, Choi SY, et al. Standardization of weed pollen extracts, Japanese hop and mugwort, in Korea. Yonsei Med J 2016;57:399-406.

11. Niemeijer NR, Kauffman HF, van Hove W, Dubois AE, de Monchy JG. Effect of dilution, temperature, and preservatives on the long-term stability of standardized inhalant allergen extracts. Ann Allergy Asthma Immunol 1996;76:535-540. 